\title{
REGIONAL \& MULTI-SECTOR INPUT-OUTPUT MODEL FOR THE CZECH REPUBLIC
}

\author{
KATEŘINA GAWTHORPE \\ University of Economics Prague, Faculty of Business Administration, \\ Department of Microeconomics, W. Churchill 4 Sq., Prague 3, Czech Republic \\ email: xzimk04@gmail.com \\ KAREL ŠAFR \\ University of Economics Prague, Faculty of Informatics and Statistics, \\ Department of Economic Statistics, W. Churchill 4 Sq., Prague 3, Czech Republic \\ email: karelsafr@gmail.com
}

\begin{abstract}
Central authorities as well as many other institutions around the world base their economic predictions on simulations of Dynamic Stochastic General Equilibrium models. The Czech central institutions utilize so-called New Keynesian type of DSGE model. Variant of the Czech Ministry of Finance model Hubert will serve as a benchmark model in this study. As well as the original model, the composition of the model will incorporate New Keynesian characteristics such as price or wage stickiness. Furthermore, the model is extended for features which allow a detailed disaggregation of the initial model into eight regions and eight sectors. The generous dataset from the Czech Statistical Office offers aggregate data as well as regional input-output tables. These data allow precise estimation of individual parameters. The applied method can be of use to other analysts or central authorities questioning the varying impact of policies on regional but also sectoral-level.
\end{abstract}

Key words: DSGE, regional model, multi-sector model, input-output

JEL Codes: E170, C680

DOI: 10.15611/amse.2017.20.13

\section{Introduction}

Dynamic Stochastic General Equilibrium models have become a standard tool for policy analysis for variety of reasons. The explicit introduction of objective function and constraint and thereafter derivation of prices and allocations is especially attractive. To allow clear identification of the interdependency between variables in the model on the macroeconomic level, the variables in the model represent aggregate values in the economy. This simplification favors analysis of the main linkages in the economy along with a good understanding of the background for a simulation outcome.

Aggregate character of the models though suffers from weaknesses. While it allows researchers to disclose basic relation, they lack deeper understanding behind their structure. The overall model signals which variables are the most sensitive to a shock but it lacks to explain the background behind such scene. Various regions but also sectors react differently to a homogenous shock. The heterogeneous vulnerability of these entities is then of an interest to all policy makers who draw decisions over where to direct subsidies or which goods are less elastic to higher taxation. Knowledge of regional and sectoral disaggregation also enables 
monetary-policy makers to target regional/sectoral inflation rates as authors Aoki (2001), Benigno (2004) and Huang and Liu (2004) advocate. Their papers find higher welfare from targeting sectoral inflation rates. Finally, such measure allows deeper understanding of the costs for a country to represent optimal currency area in line with the idea of Mundell (1961).

This study presents such useful policy tool in the form of the DSGE model accounting for sectoral and regional heterogeneity. The model is a variant of the Czech Ministry of Finance model Hubert. (Aliyev et al., 2014) It's a New Keynesian model with price and wage rigidities, Ricardian and non-Ricardian households, external habit formation and capital adjustment costs. This model abstracts from the government sector for the purpose of simpliciation. The main influential studies motivating the input-output research of the DSGE model compose of the study of Bergin and Feenstra (2000) and the papers Bouakez et al. $(2009,2014)$.

The detail of the disaggregation for the benchmark model Hubert accounts for eight sectors and eight regions. The data originates in the Czech Statistical Office dataset, which offers aggregate data as well as regional input-output tables.

The focus variable for the introduction of the sectoral/regional heterogeneity into the model is so-called Intermediate-Input variable. It reflects the flow of a firm's output demanded as an input factor in another firm. This variable though flows not only between individual sectors but also regions. It will be then subject to the highest degree of disaggregation.

The outline of the paper is as follows. The next part focuses on the mathematical extension of the original Hubert model. Subsequent section explains data for estimated parameters of the Czech Economy. Finally, the discussion of the simulated results for technology and monetary policy shock follows with comparison of the extended model with the original version. Conclusion summing up the findings can be found at the end of this paper.

\section{Model}

The extension of the Hubert model in this study diverts from the original one described in Aliyev et al. (2014) by the introduction of heterogeneous industries and regions. The model also abstracts from the fiscal sector for simplification. Given the similarity between the original and the extended version, I refer the readers to the study of Aliyev et al. (2014). The regional and industrial heterogeneity in this model concerns the production of firms. This paper therefore concentrates on the analysis of the sector of Firms.

\subsection{Households}

The model assumes a continuum of identical and infinitely - lived households indexed $j$. Only households of type "spenders" indexed by $R$ make decision based on optimization. "Savers" consumption habits are given based on their budget constraint; their labor supply is inelastic. (See also Gali et al., 2004)

The infinite stream of utility defines the preferences of Savers as:

$$
W_{t}=E_{t} \sum_{t=0}^{\infty} \beta^{n}\left[\log \left(C_{j, t+n}^{R}-H_{j, t+n}\right)-\frac{\left(N_{j, t+n}^{R}\right)^{1+\psi^{N}}}{1+\psi^{N}}\right]
$$

where $0<\beta<1$ is a subjective intertemporal discount factor and $\beta=\frac{1}{1+\bar{\omega}}$. The parameter $\bar{\omega}$ from the previous equation represents the subjective rate of time preference. The 
variable $H_{j, t}=h_{r} C_{j, t-1}$ in the utility function stands for the external habit formation. Consumption variable then represents a basket of heterogeneous final products defined in the line with the study of Dixit and Stiglitz (1977). $N_{j, t}^{R}$ labels labor supply and parameter $\psi^{N}$ the real wage elasticity of the labor supply.

The aggregate budget constraint for the savers takes the form:

$$
\begin{aligned}
& \left(1+\tau_{t}^{C}\right) P_{t}^{C} C_{j, t}^{R}+P_{t}^{I} I_{j, t}+P_{t} a\left(u_{j, t}\right) K_{j, t}^{S}+\frac{1}{R_{t}} B_{j, t+1}+\frac{1}{R_{t}^{*}+\varsigma_{t}} S_{t} B_{j, t+1}^{*} \\
& =B_{j, t}+S_{t} B_{j, t}^{*}+\left(1-\tau_{t}^{k}\right)\left[R_{t}^{k} u_{j, t} K_{j, t}^{s}+Q_{t}\right]+\left(1-\tau_{t}^{W}\right) W_{t} N_{j, t}^{R}
\end{aligned}
$$

The terms in the above equation starting from the first one on the left-hand side are consumption expenditure, expenditure on investment, followed by capital stock $K_{j, t}^{S}$ increased by the pertaining capital adjustment costs $a\left(u_{j, t}\right)$ such as in Adolfson (2007) and expenditures on domestic $B_{j, t}$ and foreign bonds $B_{j, t}^{*}$. The price of the latter bonds is converted to the Czech currency by the nominal exchange rate $S_{t}$. Premium on foreign bonds is labeled as $\zeta_{t}$.

The right-hand side of the budget constraint consists of the accumulated wealth and the earnings. The wealth consists of domestic and foreign bonds, wages $W_{t}$ and profits $Q_{t}$ from ownership of firms. Next, they earn capital rents $R_{t}^{k} u_{j, t} K_{j, t}^{s}$ where $u_{j, t}=K_{j, t} / K_{j, t}^{S}$ expresses the utilization rate of the capital stock. The capital stock $K_{j, t}^{s}$ evolves as

$$
K_{j, t+1}^{S}=(1-\delta) K_{j, t}^{S}+\left[1-\Gamma\left(\frac{I_{t}}{I_{t-1}}\right)\right] I_{t}
$$

with the depreciation rate delta and

$$
\Gamma\left(\frac{I_{t}}{I_{t-1}}\right) \equiv \frac{\kappa}{2}\left(\frac{I_{t}}{I_{t-1}}-u_{z}\right)^{2} .
$$

In the last equation $\kappa$ denotes capital adjustment costs and $\mathrm{u}_{\mathrm{z}}$ reflects a steady-state growth rate of technology. In regards to taxation $\tau_{t}^{C}$ denotes consumption tax, $\tau_{t}^{W}$ income tax and $\tau_{t}^{k}$ corporate tax rate.

Some real variables such as consumption, capital or investment in this model follow the reality of a permanent growth visible on the Czech data. To stationarize them designers of the Hubert model assume a permanent technology shock $z_{t}$. (Aliyev et al., 2014; see also Adolfson, 2007) The stochastic technology trend is defined as:

$$
u_{z, t}=\frac{z_{t}}{z_{t-1}}
$$

and 


$$
u_{z, t}=\left(1-\rho_{u z}\right) u_{z}+\rho_{u z} u_{z, t-1}+e_{t}^{u z}
$$

where $u_{z}$ is the steady-state growth rate of technology. The shock thus follows the autoregressive process with an IID-Normal error term.

Households of type spenders do not exhibit habit persistence in consumption, they do not decide over their expenditures as they spend their entire income on consumption and their labor supply is assumed to be inelastic. Their budget constraint is:

$$
\left(1+\tau_{t}^{C}\right) P_{t}^{C} C_{t}^{N}=\left(1-\tau_{t}^{W}\right) W_{t} N_{j, t}^{N}+\tau_{t}^{b} W_{b}\left(N_{j, t}^{N}-L_{j, t}^{N}\right)+T R_{t}
$$

with real expenditure on consumption $C_{t}^{N}$ with price $P_{t}^{C}$. The income for the spenders originates as wages from the labor supply $N_{j, t}^{N}$, the unemployment benefits $\tau_{t}^{b}$ multiplied by the wage bill $W_{b}$ and the unemployment rate (difference between labor supply $N_{j, t}^{N}$ and labor demand $L_{j, t}^{N}$ ) and finally by the government transfers $T R_{t}$.

Finally, such as in the original model each household $j$ of both types spenders and savers is a monopoly supplier of differentiated labor $N$. (See Aliyev et al., 2014)

The results of the maximization problem for both types of households stay identical to the Hubert version. (See Aliyev et al., 2014)

\subsection{Firm}

Continuum of firms indexed by $o \in[0,1]$, apply identical technology and produce differentiated good. Their production function in real terms appear as:

$$
Y_{t}(o)=\left(K_{t}(o)\right)^{\alpha}\left(M_{t}(o)\right)^{\beta} m\left(z_{t} L_{t}(o)\right)^{1-\alpha-\beta} m
$$

The production process is function of labor $L_{t}$, capital $K_{t}$, intermediate inputs $M_{t}$ and technology $z_{t}$ variables. Parameters $\alpha$ and $\beta$ with index m reflect the output elasticity of capital and intermediate product bundle respectively. The intermediate-input variable is a bundle of differentiated intermediate inputs employed in the sector $j$ defined as the DixitStiglitz index (see Dixit and Stiglitz, 1977):

$$
M_{t}=\left(\sum_{i=1}^{N} \chi_{j i}\left(M_{t}^{(j)}\right)^{\frac{\theta-1}{\theta}}\right)^{\frac{\theta}{\theta-1}} \text { where the sum of weights } \sum_{i=1}^{N} \chi_{i j}=1
$$

The intermediate input in the sector $j$ is further disaggregated to account for differentiated regions. Similarly, the intermediate input in the region $l$ is a bundle of differentiated inputs from the sector $j$ :

$$
M_{t}^{(j)}=\left(\sum_{l=1}^{N} \chi^{(j, l)}\left(M_{t}^{(j, l)}\right)^{\frac{\theta-1}{\theta}}\right)^{\frac{\theta}{\theta-1}} \quad M_{t}^{(l)}=\left(\sum_{j=1}^{N} \chi^{(j, l)}\left(M_{t}^{(j, l)}\right)^{\frac{\theta-1}{\theta}}\right)^{\frac{\theta}{\theta-1}}
$$

The intermediate input for the sector $j$ and the region $l$ is a bundle of intermediate inputs flowing from the region $k$ to the region 1 for the sector $\mathrm{j}$ : 


$$
M_{t}^{(j, l)}=\left(\sum_{k=1}^{N} \chi_{k}^{(j, l)}\left(M_{k, t}^{(j, l)}\right)^{\frac{\theta-1}{\theta}}\right)^{\frac{\theta}{\theta-1}}
$$

The most detail disaggregation concerns the intermediate input from region $\mathrm{k}$ to region 1 for the sector $\mathrm{j}$, which is a bundle of differentiated intermediate inputs flowing from the sector $\mathrm{i}$ to the sector $\mathrm{j}$ from the region $\mathrm{k}$ to the region $\mathrm{l}$ :

$$
M_{k, t}^{(j, l)}=\left(\sum_{k=1}^{N} \chi_{i, k}^{(j, l)}\left(M_{i, k, t}^{(j, l)}\right)^{\frac{\theta-1}{\theta}}\right)^{\frac{\theta}{\theta-1}}
$$

This representation assimilates the study of Bouakez (2005, 2009). Given these definitions, one may derive:

$$
M_{t}=\left(\sum_{j=1}^{N} \sum_{l=1}^{N} \sum_{k=1}^{N} \sum_{i=1}^{N} \chi^{(j)} \chi^{(j, l)} \chi_{k}^{(j, l)} \chi_{i, k}^{(j, l)}\left(M_{i, k, t}^{(j, l)}\right)^{\frac{\theta-1}{\theta}}\right)^{\frac{\theta}{\theta-1}}
$$

Based on the study of Gali, the prices are disaggregated for individual sectors and regions:

$$
\begin{array}{r}
H_{t}^{(j)}=\left(\sum_{i=1}^{N}\left(p \chi^{(j)}\right)^{\theta}\left(H_{i, t}^{(j)}\right)^{1-\theta}\right)^{\frac{1}{1-\theta}} \text { where the sum of weights } \sum_{i=1}^{N} p \chi^{(j)}=1 \\
H_{t}^{(j)}=\left(\sum_{l=1}^{N}\left(p \chi^{(j, l)}\right)^{\theta}\left(H_{t}^{(j, l)}\right)^{1-\theta}\right)^{\frac{1}{1-\theta}} \quad H_{t}^{(l)}=\left(\sum_{j=1}^{N}\left(p \chi^{(j, l)}\right)^{\theta}\left(H_{t}^{(j, l)}\right)^{1-\theta}\right)^{\frac{1}{1-\theta}} \\
H_{t}^{(j, l)}=\left(\sum_{k=1}^{N}\left(p \chi_{k}^{(j, l)}\right)^{\theta}\left(H_{k, t}^{(j, l)}\right)^{1-\theta}\right)^{\frac{1}{1-\theta}} \quad H_{k, t}^{(j, l)}=\left(\sum_{k=1}^{N}\left(p \chi_{i, k}^{(j, l)}\right)^{\theta}\left(H_{i, k, t}^{(j, l)}\right)^{1-\theta}\right)^{\frac{1}{1-\theta}}
\end{array}
$$

Alike the consumption expenditure, the identity for the intermediate inputs expenditure is

$$
H_{t}^{(j)} M_{t}^{(j)}(o)=\sum_{i=1}^{N} H_{i, t}^{(j)} M_{i, t}^{(j)}(o)
$$

This relationship is also valid for different levels of disaggregation of the variables.

To derive the relationship for the intermediate-input demands flowing from the sector $i$ to the sector $j$ and from the region $k$ to the region $l$, the utilized equation for the intermediateinput expenditure is:

$$
H_{t} M_{t}(o)=\sum_{j=1}^{N} \sum_{l=1}^{N} \sum_{k=1}^{N} \sum_{i=1}^{N} H_{i, k, t}^{(j, l)} M_{i, k, t}^{(j, l)}(o)
$$

Optimization of the input demand flowing between regions and sectors with respect to the relation for the intermediate-input expenditure yields:

$$
M_{i, k, t}^{(j, l)}=\left(\chi^{j} \chi^{j, l} \chi_{k}^{j, l} \chi_{i, k}^{j, l}\right)^{\theta}\left(\frac{H_{i, k, t}^{(j, l)}}{H_{t}}\right)^{-\theta} M_{t}
$$


The variables capital $K_{t}$ and labor $L_{t}$ are also subject to disaggregation. The level of their disaggregation is though limited to individual sectors and regions without further disaggregation, which would capture flows between regions or industries. The disaggregation of capital follows the same procedure as intermediate inputs:

$$
\begin{aligned}
& K_{t}^{(j)}=\left(\sum_{l=1}^{N} \gamma^{(j, l)}\left(K_{t}^{(j, l)}\right)^{\frac{\theta-1}{\theta}}\right)^{\frac{\theta}{\theta-1}} \text { with price } R_{t}^{K(j)}=\left(\sum_{l=1}^{N}\left(\gamma^{(j, l)}\right)^{\theta}\left(R_{t}^{K(j, l)}\right)^{1-\theta}\right)^{\frac{1}{1-\theta}} \\
& K_{t}=\left(\sum_{j=1}^{N} \gamma^{(j)}\left(K_{t}^{(j)}\right)^{\frac{\theta-1}{\theta}}\right)^{\frac{\theta}{\theta-1}} \quad \text { with price } R_{t}^{K}=\left(\sum_{j=1}^{N}\left(\gamma^{(j)}\right)^{\theta}\left(R_{t}^{K(j)}\right)^{1-\theta}\right)^{\frac{1}{1-\theta}}
\end{aligned}
$$

Disaggregation of labor is similar:

$$
\begin{aligned}
& L_{t}^{(j)}=\left(\sum_{l=1}^{N} \gamma^{(j, l)}\left(L_{t}^{(j, l)}\right)^{\frac{\theta-1}{\theta}}\right)^{\frac{\theta}{\theta-1}} \text { with price } W_{t}^{(j)}=\left(\sum_{l=1}^{N}\left(\gamma^{(j, l)}\right)^{\theta}\left(W_{t}^{(j, l)}\right)^{1-\theta}\right)^{\frac{1}{1-\theta}} \\
& L_{t}=\left(\sum_{j=1}^{N} \gamma^{(j)}\left(L_{t}^{(j)}\right)^{\frac{\theta-1}{\theta}}\right)^{\frac{\theta}{\theta-1}} \text { with price } W_{t}=\left(\sum_{l=1}^{N}\left(\gamma^{(j)}\right)^{\theta}\left(W_{t}^{(j)}\right)^{1-\theta}\right)^{\frac{1}{1-\theta}}
\end{aligned}
$$

To derive optimal input demands in the detrended form, one needs to stationarize values for the capital and the intermediate-inputs, as these two variables follow clear trend on the Czech data. In correspondence to the Ministry of Finance model, individual variables are growing by the size $z_{t}$. The reason for not detrending the output is its subsequent inclusion for simulating the monetary-policy rule, where central bank bases its policy on nonstationarized evolution of aggregate output and inflation rate. Then the stationarized production function rewrites as:

$$
Y_{t}(o)=z_{t}\left(K_{t}(o)\right)^{\alpha}\left(M_{t}(o)\right)^{\beta} m\left(L_{t}(o)\right)^{1-\alpha-\beta} m
$$

Maximizing this production function (24) in respect to the detrended total cost function where again labor demand does not follow a trend and thus is not subject of stationarization:

$$
T C_{t}(o)=R_{t}^{K} K_{t}(o)+W_{t} L_{t}(o)+H_{t} M_{t}(o)
$$

yields the optimal intermediate-input, labor and capital demand:

$$
\begin{gathered}
M_{t}^{(*)}(o)=Y_{t}(o) \frac{\left(R_{t}^{k}\right)^{\alpha} W_{t}^{1-\alpha-\beta}}{z_{t} H_{t}^{1-\beta_{m}}}\left(\frac{\beta_{m}}{1-\alpha-\beta_{m}} \frac{1-\beta_{m}}{\frac{1-\alpha-\beta_{m}}{\alpha}}\right) \\
L_{t}^{(*)}(o)=Y_{t}(o) \frac{\left(H_{t}\right)^{\beta_{m}}\left(R_{t}^{k}\right)^{\alpha}}{z_{t} W_{t}^{\frac{\alpha+\left(1-\alpha-\beta_{m}\right) \beta_{m}}{1-\beta_{m}}}}\left(\frac{1-\alpha-\beta_{m}}{\beta_{m}}\right)^{\beta_{m}}\left(\frac{1-\alpha-\beta_{m}}{\alpha}\right)^{\frac{\alpha-\alpha \beta_{m}}{1-\beta_{m}}}
\end{gathered}
$$




$$
K_{t}^{(*)}(o)=Y_{t}(o) \frac{\left(H_{t}\right)^{\beta_{m}} W_{t}^{1-\alpha-\beta_{m}}}{z_{t}\left(R_{t}^{k}\right)^{\frac{\alpha \beta_{m}+\left(1-\alpha-\beta_{m}\right)}{1-\beta_{m}}}}\left(\frac{1-\alpha-\beta_{m}}{\beta_{m}}\right)^{\beta_{m}}\left(\frac{\alpha}{1-\alpha-\beta_{m}}\right)^{\frac{1-\alpha-\beta_{m}+\alpha \beta_{m}}{1-\beta_{m}}}
$$

As one might notice, prices are not stationarized in the model, as they do not follow a trend. This view corresponds to the original Hubert model. (Aliyev et al., 2014) The next section explains the price setting behavior of firms for final but also intermediate products.

\subsection{Price-setting behavior}

The $1-\rho$ fraction of firms set optimal prices in period $t$ while the rest sets their prices equal to the lagged inflation. The derivation of the traditional New Keynesian Phillips curve (NKPC) for prices and wages follows the model of Hubert. (See Aliyev et al., 2014) The only difference stems from the introduction of the intermediate-input variable along with sectoral and regional heterogeneity. Such modification affects the marginal costs' equation:

$$
M C_{t}^{(j, l)}=\beta_{m}{ }^{(j, l)} H_{t}^{(j, l)}+\alpha^{(j, l)} R_{t}^{K(j, l)}+\left(1-\alpha^{(j, l)}-\beta_{m}{ }^{(j, l)}\right) W_{t}^{(j, l)}-z_{t}
$$

The output price equation for region 1 and sector $\mathrm{j}$ is then:

$$
P_{t}^{(j, l)}=\frac{\rho}{1+\beta \rho^{2} u_{z}} P_{t-1}^{(j, l)}+\frac{\beta \rho u_{z}}{1+\beta \rho^{2} u_{z}} P_{t+1}^{(j, l)}+\frac{(1-\rho)\left(1-\beta \rho u_{z}\right)}{1+\beta \rho^{2} u_{z}} M C_{t}^{(j, l)}
$$

while the equation for the price of output stays identical to the original version.

Decision over prices for the intermediate inputs is assumed to follow similar pattern such as over prices for final products. Again, only fraction of firms set their prices optimally in period $t$. Following the same procedure as for calculating the prices of output, one derives loglinearized equations in this form:

$$
H_{t}^{(j, l)}=\frac{\rho}{1+\beta \rho^{2} u_{z}} H_{t-1}^{(j, l)}+\frac{\beta \rho u_{z}}{1+\beta \rho^{2} u_{z}} H_{t+1}^{(j, l)}+\frac{(1-\rho)\left(1-\beta \rho u_{z}\right)}{1+\beta \rho^{2} u_{z}} M C C_{t}^{(j, l)}
$$

with marginal costs function:

$$
M C C_{t}^{(j, l)}=\alpha^{(j, l)} R_{t}^{K(j, l)}+\left(1-\alpha^{(j, l)}\right) W_{t}^{(j, l)}-z_{t}
$$

As one may notice the marginal costs equation for intermediate-input prices does not contain the variable for intermediate-input prices as this variable does not enter the total costs function:

$$
T C C_{t}(o)=R_{t}^{K} K_{t}(o)+W_{t} L_{t}(o)
$$

By other words, firms make their decision over intermediate-input prices based on the total costs connected with the production of intermediate inputs. Intermediate inputs sold to other firms are outputs of the production procedure. The production leading to such products sold to other firms depends on primary inputs: capital and labor. In the next step, firm utilizes intermediate inputs bought from other firms, labor and capital to produce final products with prices in equation 30. The difference in the production of intermediate inputs and final products is then use of only primary inputs and inputs consisting also of intermediate inputs respectively.

The rest of the model, the foreign sector and the labor market with staggered wage-setting stay alike the Hubert version. (Aliyev et al., 2014) Simulation of the model then utilizes the above-stated equations combined with those from the remaining sections as outlined in the 
Hubert model. (Aliyev et al., 2014) The next part of the study concerns parameter estimation necessary for the final simulation.

\section{Model Estimation}

Although the above derived model allows any level of disaggregation, the model in this study consists of eight regions and eight industries.

The sector "1" stands for the sector of Agriculture CZ-CPA 1-3, "2" for the Mining sector CZ-CPA 5-9, "3" for the Industrial sector CZ-CPA 10-33, "4" for the Energetic sector CZCPA 35, "5" for the Construction CZ-CPA 41-43, " 6 " for the Financial sector CZ-CPA 64-66, "7" for the Services CZ-CPA 45-56 and " 8 " is the sector composed of the industries producing remaining products not produced in the previous ones. The region " 1 " labels the region of Prague CZ01, "2" the Central Bohemian region CZ02, "3" the South-West CZ03, "4" the North-West CZ04, "5" the North-East CZ05, "6" the South-East CZ06, "7" the Central Moravian CZ07 and "8" the Moravian-Silesian region CZ08. The data originates in the Czech Statistical Office dataset, which offers aggregate data as well as regional inputoutput tables.

Input-output matrices from the Czech Statistical Office contain the necessary data for the estimation procedure of the IO parameters such as for the weights parameters in the composite indexes. These matrices are available with the time span of five years. The selected year for the estimated parameters is 2010. Vector autoregressive models then represent the applied method to estimate the production function parameters using the time-series from 1995 until 2014 available on the website of the Czech Statistical Office. Hubert model provides estimates for the rest of the parameters. (Aliyev et al., 2014)

The aggregate parameter values used for estimation are available on the table 1 . The parameters values disaggregated for individual sectors and regions are not presented due to the rich amount of these parameters counting to over nine thousand. The parameters subject to such disaggregation are the parameters: $\chi^{(j)}, \chi^{(j, l)}, \chi_{k}^{(j, l)}, \chi_{i, k}^{(j, l)}, p \chi^{(j)}, p \chi^{(j, l)}, p \chi_{k}^{(j, l)}, p \chi_{i, k}^{(j, l)}$ and $\beta_{m}{ }^{(j, l)} \alpha^{(j, l)}$. The rest of the input-output parameters such as the share of labor or capital inputs for individual sector or region in the aggregate labor, capital variables are set equal to $1 / 8$. These variables are set homogenous across sectors or regions.

The input-output coefficients were calibrated for the year 2011 based on data from the Faculty of Statistics and Informatics, Department of Economic Statistics and the Czech Statistical Office, namely annual national account data. To compute the regional inflation of outputs we employ regional input-output tables and regional accounts from the Czech Statistical Office. The methodology for the construction of the input-output tables originate in the study of Sixta \& Vltavska (2016) and in the study for inter-regional flows from Safr (2016a). The summary statistics for the coefficients of individual sectors and regions are present on the table 2 .

\section{Results}

While the description of the model does not directly insinuate the enormous size of the model; the model consists of over 15,000 equations. We recommend researchers tempted to simulate such model to create extra m-file script with a code, which creates the entire mod-file script. The longevity of running such model motivates to decrease the presentation of the outcome to two types of shocks. Namely, the figures in this part of the paper illustrates the degree of heterogeneity among sectors/regions in respect to monetary policy shock and shock into intermediate-input price of the sector 1. 


\subsection{Monetary policy shock}

The illustration of the restrictive monetary policy shock with realization of size 1 on the figure 2 for both versions of models displays the same direction of the effect of the shock on aggregate variables alike the Galí's model (2008, p. 57).

The calibration method significantly affects the model output resulting in the homogenous impact of shocks on regions (the aggregate effect for region is homogenous while the products in regions might stay heterogeneous). This is caused by the applied RAS method used for the calibration of individual values for coefficients of the production function and AR lags. Utilization of such technique aims to overcome missing regional structure in data necessary for the model estimation.

The restrictive monetary policy shock into the interest rate as well as the other shocks fully reflects this calibration procedure of data estimation. Figure 1 illustrates these impacts of the shock. The most sizable effects are visible for the sectors 3,6 and 1. This outcome perfectly corresponds to the sectorial structure of the economy. The most sensitive sectors towards the shock are then the Industrial sector and the Financial services. This output is also compatible with a similar shock into the structural model of Bouakez et al. $(2014,57)$. The model of those authors demonstrates the highest sensitive of Industrial, followed by Financial and finally Agricultural sector towards such shock. This result stems from the high sensitivity of these sectors to the interest rate changes. This is a common characteristic of the sectorial structure of the economy and that is why such congruence of output is important. Regarding the regional responsiveness towards the shock, the shocks show to deliver homogenous results as aggregate.

The next analyzed shock is the shock into the intermediate-input price of the sector one. This type of shock is interesting to study as it displays the flow of the impact of the shock into one sector on other sectors. We focus on the shock into the sector of Agriculture and display the effect of the shock on the output prices and outputs. By principle, the first sector is the most sensitive one towards this shock. For this reason, the impact of the sector 1 on the shock is not present in the figures as it would disable to see in detail the heterogeneity of reaction for the remaining sectors.

The most vulnerable sector towards this shock is the sector 7 namely Services including accommodation and others in the classification CZ-CPA 45-46. This result is verified by reality where the products of the first sector represent the main inputs into the production procedure for the sector 7 . The outputs of regions as aggregate seem to react homogenously to the shock. In contrast, the reaction of outputs to the shock is very heterogeneous between sectors. The production of the Mining and the Financial sector then reacts negatively to the shock due to the growth of their respective input prices.

\section{Conclusion}

This research study constructs highly disaggregated DSGE model accounting for asymmetries in eight Czech sectors and eight regions. This multi-sector multi-regional model combines the advantages of macroeconomic model with input-output and regional data. The model is heterogeneous in production process where intermediate inputs flow between individual sectors and regions. The weights of capital and labor on production also vary across sector and regions in the model. This advanced originally Ministry of Finance model allows more thorough analysis of the structure of the Czech economy.

This article presents impact evaluation for the monetary policy shock and shock into the intermediate-input price of the sector 1 . Regional differences appear to be minimal, while 
there shows to be high heterogeneity in reaction of individual sectors. This model proves to be able to diagnose the flow of the effect of the shock from one sector to others.

The next research will focus on the introduction of asymmetry into other parameters such as coefficients for exports and imports between regions.

\section{Acknowledgements}

This work was supported by the University of Economics, Prague, Faculty of Informatics and Statistics in collaboration with the Faculty of Business Administration under the Grant Internal Grant Agency, project No. 28/2017 "Regional statistics structures" and by Institutional Support for Long Period and Conceptual Development of Research and Science at the Faculty of Informatics and Statistics, University of Economics Prague.

\section{References}

[1] Adolfson, M., Laséen, S., Lindé, J., Villani, M. 2007. Bayesian Estimation of an Open Economy DSGE Model with Incomplete Pass-Through. Journal of International Economics, vol. 72, iss. 2, pp. 481-511. doi:10.1016/j.jinteco.2007.01.003.

[2] Aliyev, I., Bobková, B. Štork, Z. 2014. Extended DSGE Model of the Czech Economy. Ministry of Finance of the Czech Republic, http://www.mfcr.cz/.

[3] Aoki, K. Optimal Monetary Policy Responses to Relative-Price Changes. 2001. Journal of Monetary Economics, vol. 48, iss. 1, pp. 55-80. doi:10.1016/S0304-3932(01)00069-1.

[4] Benigno, P. Optimal Monetary Policy in a Currency Area. Journal of International Economics, vol. 63, iss. 2, pp. 293-320. doi:10.1016/S0022-1996(03)00055-2.

[5] Bergin, P. R., Feenstra, R. C. 2001. Pricing-to-Market, Staggered Contracts, and Real Exchange Rate Persistence. Journal of International Economics, vol. 54, iss. 2, pp. 333-59. doi:10.1016/S0022-1996(00)00091-X.

[6] Bouakez, H., Cardia, E., Ruge-Murcia, F. J. 2009. Sectoral Price Rigidity and Aggregate Dynamics. SSRN Scholarly Paper. Rochester, NY: Social Science Research Network, http://papers.ssrn.com/abstract=1349107.

[7] Bouakez, H., Cardia, E., Ruge-Murcia, F. J. 2005. The Transmission of Monetary Policy in a Multisector Economy. International Economic Review, vol. 50, iss. 4, pp. 1243-66. doi:10.1111/j.1468-2354.2009.00567.x.

[8] Dixit, A. K., Stiglitz, J. E. 1977. Monopolistic Competition and Optimum Product Diversity. 1977. The American Economic Review, vol. 67, iss. 3, pp. 297-308.

[9] Galí, J. 2008. Monetary Policy, Inflation, and the Business Cycle: An Introduction to the New Keynesian Framework. Princeton, N.J: Princeton University Press.

[10] Gali, J., Lopez-Salido, J. D., Valles, J. 2004. Rule-of-Thumb Consumers and the Design of Interest Rate Rules. Working Paper. National Bureau of Economic Research. doi:10.3386/w10392.

[11]Huang, K. X. D., Liu, Z. 2005. Inflation Targeting: What Inflation Rate to Target?” Journal of Monetary Economics, vol. 52, iss. 8, pp. 1435-62. doi:10.1016/j.jmoneco.2004.08.008.

[12]Mundell, R. A. 1961. A Theory of Optimum Currency Areas. The American Economic Review, vol. 51, iss. 4, pp. 657-65.

[13]Sixta, J., Vltavska, K. 2016. Regional Input-Output Tables: Practical Aspects of its Compilation for the Regions of the Czech Republic. Ekonomicky casopis, vol. 64, no. 1, 2016, pp. $56-69$.

[14]Safr, K. 2016. Allocation of commodity flows in the regional Input-Output tables for the Czech Republic. Proceedings of $19^{\text {th }}$ International Scientific Conference Application of Mathematics and Statistics in Economics. 31. 8. - 4. 9. 2016, Banska Stiavnica. 


\section{Appendix}

Table 1: Parameter estimates

\begin{tabular}{crrrcr}
\hline Parameter & Value & Parameter & Value & Parameter & Value \\
\hline$\psi^{N}$ & 1.5 & $\epsilon_{p}$ & 0.2 & $\omega_{s n x}$ & 0.25 \\
$\omega_{s s}$ & 0.5 & $\epsilon_{w}$ & 0.52 & $\beta$ & 0.99 \\
$\omega_{s i}$ & 0.5 & $\phi_{r}$ & 1.5 & $\alpha_{\mathrm{R}}$ & 0.32 \\
$\rho_{p *}$ & 0.5 & $\theta$ & 2 & $\delta$ & 0.01 \\
$\rho_{R}$ & 0.52 & $\theta_{c}$ & 0.3 & $\lambda_{\pi}$ & 1.5 \\
$\rho_{t c}$ & 0.6 & $\theta_{c *}$ & 0.3 & $\lambda_{y}$ & 0.5 \\
$\rho_{t k}$ & 0.91 & $\theta_{i}$ & 0.2 & $\rho_{v}$ & 0.5 \\
$\rho_{t r}$ & 0.92 & $\theta_{i *}$ & 0.2 & $\mu_{c m}$ & 0.22 \\
$\rho_{t w}$ & 0.61 & $\theta_{w}$ & 2 & $\mu_{i m}$ & 0.32 \\
$\rho_{u z}$ & 1.00 & $\kappa$ & 11 & &
\end{tabular}

These parameters' value directly affects the evolution of the aggregate variables. Their values stay alike the benchmark model from Aliyev et al. (2014).

Table 2: Average coefficients in sectors and regions:

\begin{tabular}{cccccc}
\hline Sectors & Eta & Beta & Region & Eta & Beta \\
\hline Sector 1 & 0,51 & 0,51 & Region 1 & 0,23 & 0,50 \\
Sector 2 & 0,35 & 0,35 & Region 2 & 0,25 & 0,48 \\
Sector 3 & 0,30 & 0,30 & Region 3 & 0,25 & 0,48 \\
Sector 4 & 0,50 & 0,50 & Region 4 & 0,25 & 0,48 \\
Sector 5 & 0,61 & 0,61 & Region 5 & 0,24 & 0,48 \\
Sector 6 & 0,12 & 0,12 & Region 6 & 0,25 & 0,48 \\
Sector 7 & 0,91 & 0,91 & Region 7 & 0,25 & 0,48 \\
Sector 8 & 0,56 & 0,56 & Region 8 & 0,25 & 0,48 \\
Mean & 0,24 & 0,48 & Mean & 0,24 & 0,48 \\
\hline
\end{tabular}

Source: Czech Statistical Office data and data from the Faculty of Statistics and Informatics, Department of Economic Statistics. 
20th International Scientific Conference AMSE

Applications of Mathematics and Statistics in Economics 2017

Szklarska Poręba, Poland 30 August 2017 - 3 September 2017

Figure 1: Monetary policy shock - Impact on Output
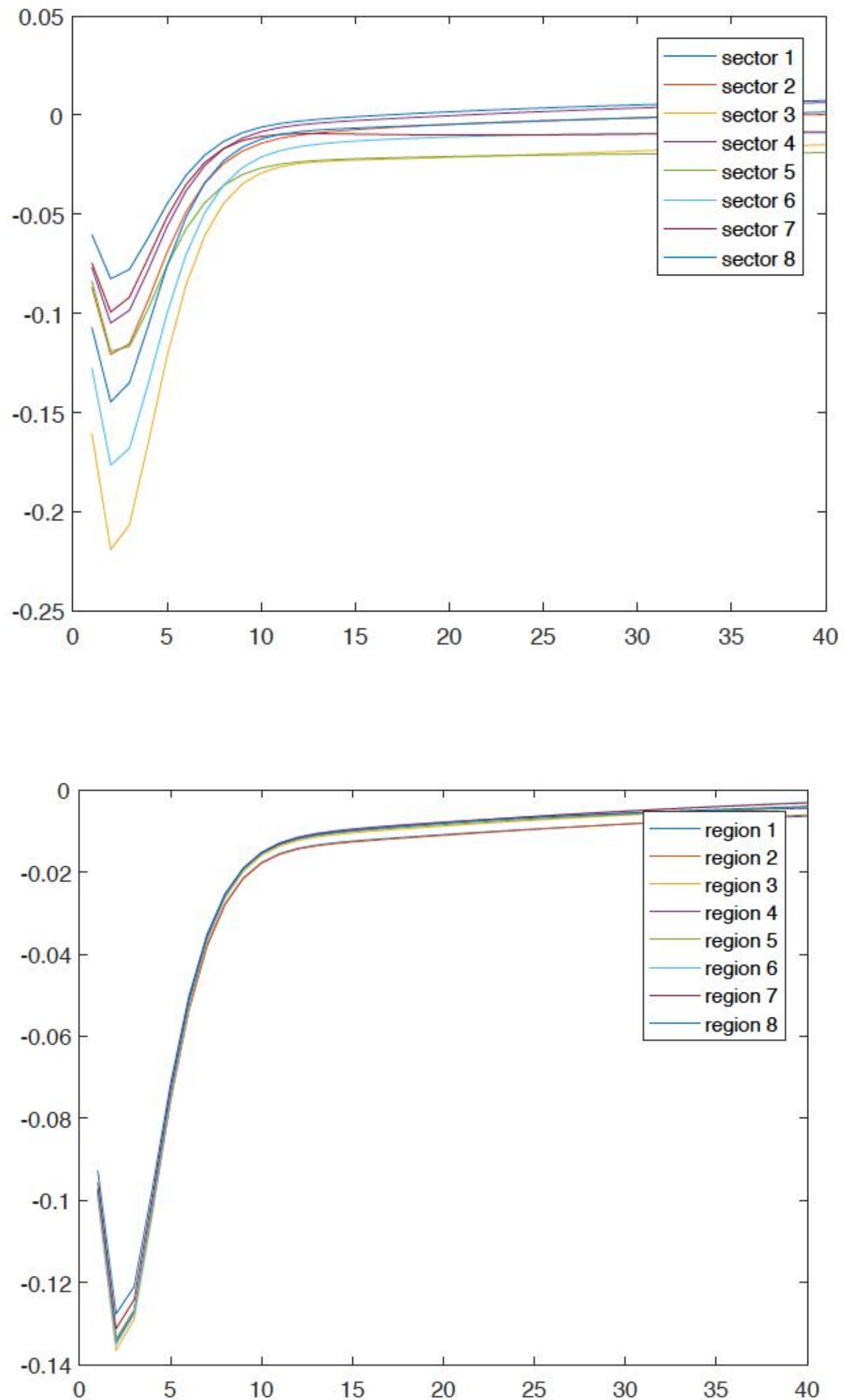

Source: Author's calculation. The y axis labels the degree of responsiveness of sectoral or regional output towards monetary policy shock.The horizontal line displays the number of simulated periods. 
Figure 2: Shock into Itermediate-Input Prices, Impact on Output Prices
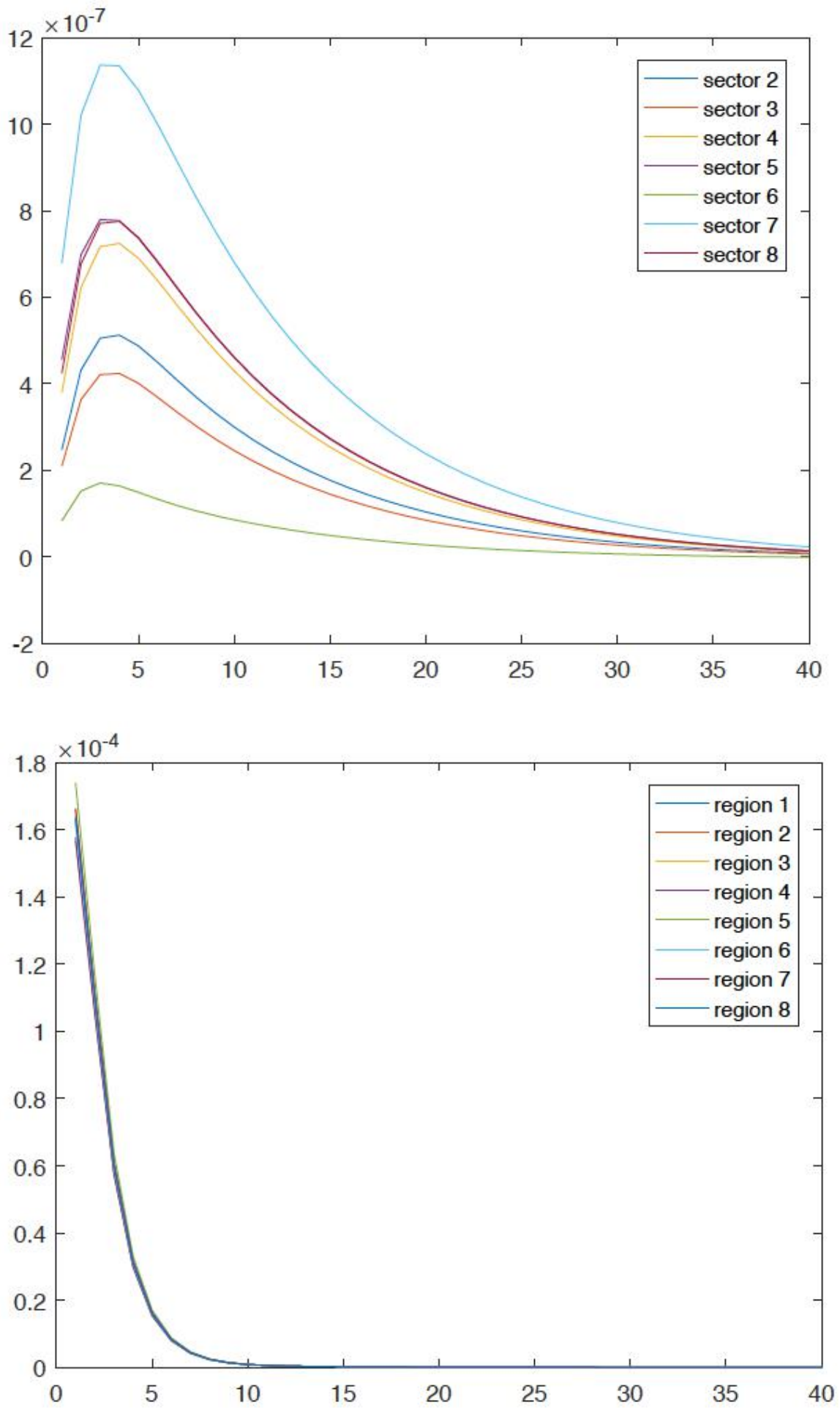

Source: Author's calculation. The y axis labels the degree of responsiveness of sectoral or regional output prices towards shock into intermediate-input prices. The horizontal line displays the number of simulated periods. 
20th International Scientific Conference AMSE

Applications of Mathematics and Statistics in Economics 2017

Szklarska Poręba, Poland 30 August 2017 - 3 September 2017

Figure 3: Shock into Intermediate-Input Prices, Impact on Output
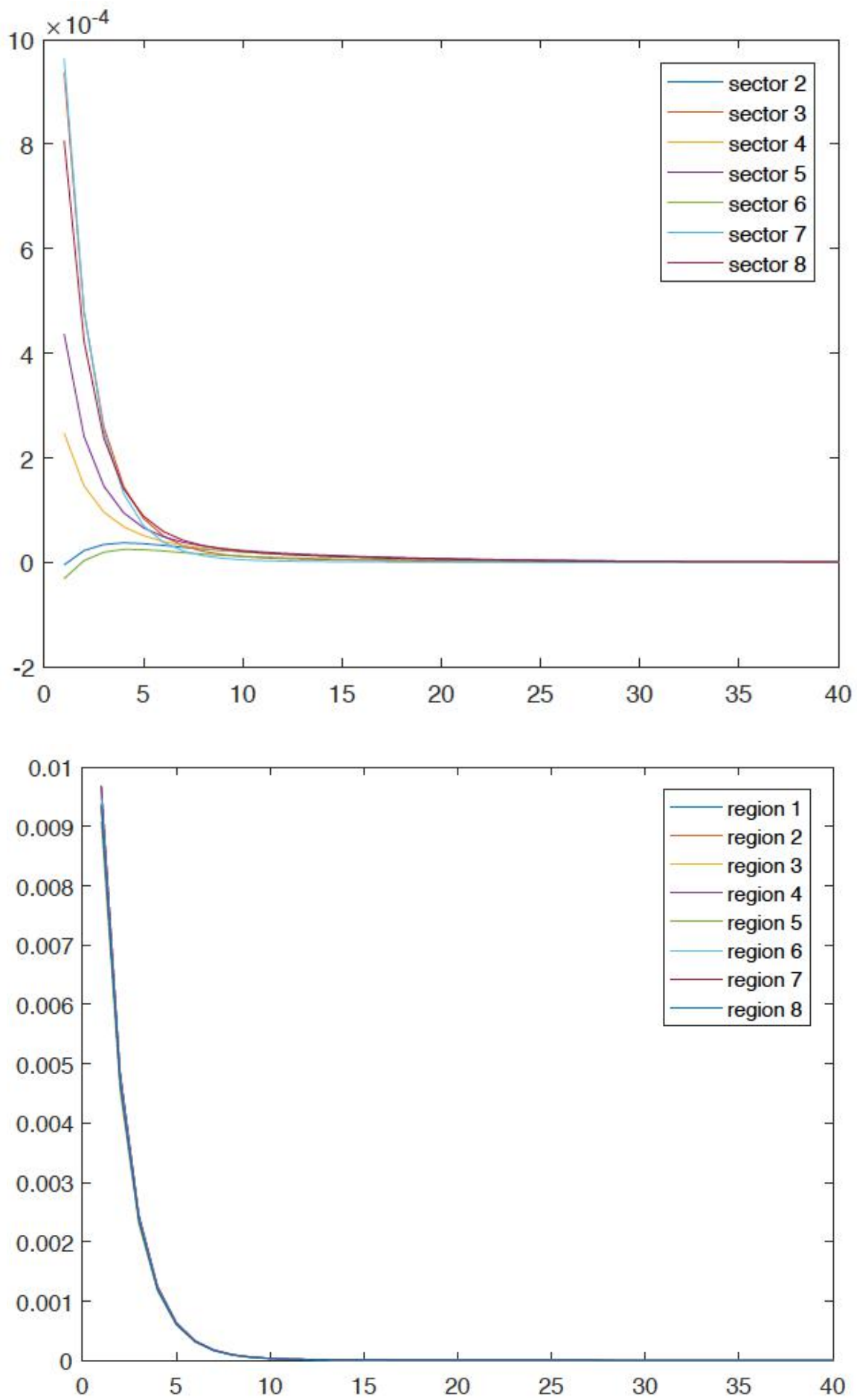

Source: Author's calculation. The y axis labels the degree of responsiveness of sectoral or regional output towards shock into intermediate-input prices. The horizontal line displays the number of simulated periods. 